\title{
Characterization of Pt-, Pd-spermine complexes for their effect on polyamine pathway and cisplatin resistance in $\mathbf{A 2 7 8 0}$ ovarian carcinoma cells
}

\author{
RAMAKUMAR TUMMALA ${ }^{1,4}$, PAULA DIEGELMAN ${ }^{1}$, SONIA M. FIUZA ${ }^{3}$, \\ LUIS A.E. BATISTA DE CARVALHO ${ }^{3}$, MARIA PAULA M. MARQUES ${ }^{3}$, \\ DEBORA L. KRAMER ${ }^{2}$, KIMBERLY CLARK ${ }^{1}$, SLAVOLJUB VUJCIC ${ }^{2}$, \\ CARL W. PORTER ${ }^{2}$ and LAKSHMI PENDYALA ${ }^{1}$
}

Departments of ${ }^{1}$ Medicine, ${ }^{2}$ Pharmacology and Therapeutics, Roswell Park Cancer Institute, Buffalo, NY 14263, USA; ${ }^{3}$ Research Unit 'Molecular Physical Chemistry', University of Coimbra, Portugal

Received December 21, 2009; Accepted February 16, 2010

DOI: $10.3892 /$ or_00000823

\begin{abstract}
We have previously showed that platinum drugs up-regulate SSAT and SMO and down-regulate ODC and SAMDC in the polyamine pathway. Several studies including our own established that platinum drugs combined with polyamine analog DENSPM produces synergistic increase in SSAT activity with polyamine depletion. Since polyamine pathway is an important therapeutic target, we investigated whether agents containing both platinum and polyamines have similar effects on the polyamine pathway. Two complexes i) Pt-spermine with two cisplatin molecules linked to a spermine in the center and ii) Pd-spermine with similar structure i, but Pd (II) substituted for Pt (II) were analyzed with respect to their effect on the expression of genes in polyamine pathway, SSAT and SMO protein expression, SSAT activity and polyamine pools. Pt-, Pd-spermine complexes induced significant down-regulation of SMO, arginase 2 and NRF-2, with no change in SSAT, while cisplatin as a single agent or in combination with DENSPM induced significant up-regulation of SSAT and SMO. The SSAT activity was not induced by either Pt- or Pd-spermine
\end{abstract}

Correspondence to: Dr Lakshmi Pendyala, Department of Medicine, Roswell Park Cancer Institute, Elm and Carlton Streets, Buffalo, NY 14263, USA

E-mail: lakshmi.pendyala@roswellpark.org

Present address: ${ }^{4}$ Department of Urology, UC Davis Medical Center, Sacramento, CA 95817, USA

Abbreviations: DENSPM, $N^{l} N^{l 1}$-diethylnorspermine; Pt, platinum; Put, putrescine; Spd, spermidine; Spm, spermine; SSAT, spermidine/spermine $N^{l}$-acetyltransferase (also known as SSAT-1); SMO, spermine oxidase; ODC, ornithine decarboxylase; SAMDC, S-adenosylmethionine decarboxylase; SRB-B, sulforhodamine blue; TLDA, Taqman low-density array

Key words: spermine complexes, polyamine, cisplatin, ovarian carcinoma in A2780 cells; SMO protein levels were significantly elevated compared to the no-drug control and to a similar extent as cisplatin/DENSPM. The Pd-spm treatment induced a fall in putrescine levels to $33 \%$, spermidine to $62 \%$ and spermine to $72 \%$ while Pt-spm did not induce such a decline. Comparative cytotoxicity studies in A2780 cells indicated the potency to be cisplatin $>$ Pd-Spm $>$ Pt-Spm. Although both complexes exhibit a lower potency, the degree of resistance itself is much lower for Pt-spermine and Pd-spermine in that order (2.5 and 7.5, respectively) compared to cisplatin ( 12) as tested in cisplatin resistant A2780/CP cells. These studies suggest that Pd (II)-polyamine complexes may constitute a promising group of inorganic compounds for further studies in the development of novel chemotherapy/adjuvant chemotherapy strategies.

\section{Introduction}

Cisplatin is the prototype platinum drug that plays a central role in cancer chemotherapy. The mode of action of this platinum drug and mechanisms for resistance are well documented over the years. The principal mechanism of action is believed to be the damage to DNA by forming adducts with it, that not only prevents DNA from replication and transcriptional activities, but the DNA damage also induces down-stream signaling leading to apoptotic cell death (1). Mechanisms of resistance to the drug include impaired drug accumulation, inactivation of the drug by thiols, enhanced DNA repair and altered down-stream signaling (2-5). Our Affymetrix studies have shown that as single agents, platinum drugs impact on the polyamine pathway, up-regulating the key catabolic pathway gene spermine, spermidine $N^{I}$-acetyl transferase (SSAT) and down-regulating the biosynthetic pathway genes ornithine decarboxylase (ODC) and S-adenosylmethionine decaboxylase (SAMDC) (6). Our studies have shown that while platinum drugs oxaliplatin and cisplatin are potent inducers of SSAT gene expression, the mRNA is not translated proportionally to SSAT activity, but when combined with the polyamine analog $N^{I} N^{I I}$-diethylnorspermine (DENSPM) a synergistic increase in SSAT activity occurs, 
resulting in significant polyamine pool depletion $(7,8)$. Polyamines are required for cell proliferation (9) and the levels of polyamines are higher in tumor tissue compared with the non-tumor counterparts $(10,11)$. Polyamine pool depletion has been used as cancer therapeutic strategy (12). DENSPM up-regulates SSAT and down-regulates the biosynthetic pathway enzymes ODC and SAMDC causing depletion of polyamine pools and this analog has been tested in Phase I and Phase II clinical trials (13-16) and had no demonstrable single agent activity. Our studies and others have shown that when platinum drugs are combined with DENSPM, the synergistic SSAT activity and polyamine pool depletion that occurs in tumor cells is significantly greater than that by either of the single agents $(7,17,18)$.

The biogenic polyamine spermine is able to form chelates with several metal ions providing flexible linkers and conferring hydrophobic character to the molecule, which is important for drug uptake and enables a distinct interaction with DNA when compared to cisplatin. The quest for new anticancer agents is not limited to the investigation of new ligands, but also accounts for the substitution of platinum by other metal centers such as palladium. In fact, despite the initial belief that Pd (II) compounds were inactive as antineoplastic agents, many have been synthesized and shown to be not only more active than cisplatin (19-21), but also more effective than their $\mathrm{Pt}$ (II) counterparts (22-24). In this regard, multinuclear Pt (II)- and Pd (II)-spermine complexes comprising cisplatinlike moieties linked by variable length alkanediammine chains were synthesized and constitute a promising class of anticancer agents, the most successful case being the trinuclear compound BBR3464 (25). These spermine complexes have been shown to possess antiproliferative properties towards human cancer cells lines $(22,23,26)$, the Pd (II)-spermine complex having a damaging interaction with both DNA and the cytoskeleton (Fiuza et al, unpublished data).

Since our studies have shown that platinum drugs in combination with polyamine analog DENSPM impact the polyamine pathway, we hypothesized that the Pt-spermine and $\mathrm{Pd}$-spermine complexes may similarly affect the expression of polyamine pathway genes and SSAT activity. As single agents these compounds consist of either two cisplatin moieties, or Pd II substituted for Pt II in cisplatin molecule, each conjugated to the polyamine spermine in the center (Fig. 1). The study presented here characterizes the effect of Pt-spermine and Pd-spermine on the expression of genes in the polyamine pathway and the genes involved in platinum drug action that were identified using oxaliplatin/DENSPM and cisplatin/ DENSPM combinations in A2780 ovarian carcinoma cell line $(27,28)$. Further, the ability of these new agents to affect the proteins levels of SSAT and SMO, and SSAT activity in these cells is tested relative to cisplatin/DENSPM. In addition, comparative cytotoxicity studies of these complexes with cisplatin were performed in parental A2780 cells and in a cisplatin resistant variant A2780/CP.

\section{Materials and methods}

Cell lines and materials. The A2780 human ovarian carcinoma cell line and the cisplatin resistant A2780/CP cell line were a gift from Dr R. Ozols (Fox Chase Cancer Center, Philadelphia, PA). Cisplatin was purchased from Sigma-Aldrich (St. Louis,
MO). DENSPM was generously provided by Dr R. Merriman from Pfizer Pharmaceuticals (Ann Arbor, MI). The Ptspermine and $\mathrm{Pd}$-spermine complexes have been synthesized as described before (26). $\left[{ }^{14} \mathrm{C}\right]$-acetyl-Coenzyme A (no. NEC313) was purchased from Perkin Elmer Life Sciences, Inc. (Waltham, MA). Protein assay reagents were from Bio-Rad laboratory (Hercules, CA).

Drug treatment conditions for polyamine pathway effects. Our previous studies have shown that high synergistic SSAT induction (both mRNA and activity) is achieved after a simultaneous treatment of cells by platinum drugs $(10 \mu \mathrm{M})$ and DENSPM $(10 \mu \mathrm{M})$ for $20 \mathrm{~h}$, cells were washed thoroughly with PBS and incubated in drug-free medium for $24 \mathrm{~h}(7,8,17)$. The post drug treatment incubation of $24 \mathrm{~h}$ in drug-free medium was based on our previous studies (6) which indicated that both cisplatin and oxaliplatin induced mRNA levels that increase with time after drug exposure with a maximum at $16-24 \mathrm{~h}$. Similar concentrations of $10 \mu \mathrm{M}$ were chosen for comparative studies for Pt-spermine and Pdspermine cells with $20 \mathrm{~h}$ exposures and $24 \mathrm{~h}$ incubation in drug free medium. At this point, cells were collected and assayed for SSAT gene expression, enzyme activity and polyamine pools.

Gene expression using Taqman ${ }^{\circledR}$ low density array. We have custom designed a 32 gene array using Taqman Low Density Array (TLDA) technology (Applied Biosystems Inc. Foster City, CA). TLDA was carried out using the 384-well microfluidic card, with 30 target genes and 2 endogenous standards. For the 32 gene format the assays were run in triplicate with 4 sample capacity per card. The TLDA cards with pre-deposited gene expression assays were purchased from AB (Foster City, CA). The card includes all the polyamine target genes, genes relevant to platinum drug action, along with some of the important cell cycle, apoptosis and antioxidant pathway genes with $B$-actin and GAPDH as the endogenous standard (Table I).

TLDA was performed using ABI 7900 HT Fast RealTime RT-PCR system with SDS 2.2 software. The concept behind it is the same as for the original Taqman Real-Time RT-PCR assays using gene specific primers and probes and quantification using comparative CT method with the endogenous standards run simultaneously on these low density arrays. The results presented here are using $\beta$-actin as the endogenous standard as has been customary for platinum, polyamine combination studies. The RQ shown in the gene expression plots is the relative quantification measure that calculates the relative quantities of expression of each of the target genes in different samples relative to a corresponding calibrator. In our experiments the calibrator is the control where cells were not treated with any drug. TLDA uses approximately $50 \mu 1$ of cDNA sample plus $50 \mu 1$ of Universal Master Mix (AB, Foster City, CA) in each of the eight ports (which equates to $1 \mu \mathrm{l}$ of the cDNA sample, mixed with $1 \mu \mathrm{l}$ of Universal Master Mix per well). Centrifugal capillary action then pulls the cDNA from the loading ports, into the 48 reaction chambers containing the genes of interest. The total RNA extraction and cDNA generation were as described previously using RNeasy columns (Qiagen, Valencia, CA) and Superscript II respectively (7). 
Table I. Genes on Taqman low density array.

\begin{tabular}{|c|c|c|}
\hline Gene symbol & Gene name & Ref. NM no. \\
\hline \multicolumn{3}{|l|}{ Polyamines } \\
\hline ODC1 & Ornithine decarboxylase 1 & NM_002539 \\
\hline AMD1 & Adenosylmethionine decarboxylase 1 & NM_001634 \\
\hline SRM & Spermidine synthase & NM_003132 \\
\hline SMS & Spermine synthase & NM_004595 \\
\hline SAT & Spermidine/spermine N1-acetyltransferase 1 & NM_002970 \\
\hline SMOX & Spermine oxidase & NM_175839 \\
\hline PAOX & Polyamine oxidase (exo-N4-amino) & NM_152911 \\
\hline ARG2 & Arginase, type II & NM_001172 \\
\hline NFE2L2 & Nuclear factor, erythroid derived 2, like 2 & NM_006164 \\
\hline \multicolumn{3}{|l|}{ Platinum } \\
\hline SLC22A1 & Solute carrier family 22 (organic cation transporter), member 1 & NM_003057 \\
\hline SLC22A2 & Solute carrier family 22 (organic cation transporter), member 2 & NM_153191 \\
\hline ERCC1 & $\begin{array}{l}\text { Excision repair cross-complementing rodent repair deficiency, complementation } \\
\text { group } 1 \text { (includes overlapping antisense sequence) (Homo sapiens) }\end{array}$ & NM_001983 \\
\hline XPA & Xeroderma pigmentosum, complementation group A & NM_000380 \\
\hline GCLC & Glutamate-cysteine ligase ( $\gamma$-glutamylcysteine synthetase) & NM_001498 \\
\hline GGT1 & $\gamma$-glutamyltransferase 1 & NM_013430 \\
\hline SLC22A1 & Solute carrier family 22 (organic cation transporter), member 1 & NM_003057 \\
\hline SLC22A2 & Solute carrier family 22 (organic cation transporter), member 2 & NM_153191 \\
\hline ERCC1 & $\begin{array}{l}\text { Excision repair cross-complementing rodent repair deficiency, complementation } \\
\text { group } 1 \text { (includes overlapping antisense sequence) (Homo sapiens) }\end{array}$ & NM_001983 \\
\hline \multicolumn{3}{|l|}{ Antioxidant } \\
\hline GPX1 & Glutathione peroxidase 1 & NM_000581 \\
\hline SOD1 & Superoxide dismutase 1 & NM_000454 \\
\hline GSR & Glutathione reductase & NM_000637 \\
\hline PTGS2 & $\begin{array}{l}\text { Prostaglandin-endoperoxide synthase } 2 \text { (prostaglandin G/H synthase and } \\
\text { cyclooxygenase) }\end{array}$ & NM_000963 \\
\hline OGG1 & 8-oxoguanine DNA glycosylase & NM_016819 \\
\hline NFKB1 & Nuclear factor of kappa light polypeptide gene enhancer in B-cells 1 (p105) & NM_003998 \\
\hline PPARG & Peroxisome proliferative activated receptor, $\gamma$ & NM_138712 \\
\hline GPX1 & Glutathione peroxidase 1 & NM_000581 \\
\hline \multicolumn{3}{|l|}{ Cell cycle } \\
\hline CDKN1A & Cyclin-dependent kinase inhibitor 1A (p21, Cip1) & NM_078467 \\
\hline MDM2 & Transformed 3T3 cell double minute 2, p53 binding protein (mouse) & NM_002392 \\
\hline CCND1 & Cyclin D1 & NM_053056 \\
\hline PCNA & Proliferating cell nuclear antigen & NM_002592 \\
\hline \multicolumn{3}{|l|}{ Apoptosis } \\
\hline BCL2 & B-cell CLL/lymphoma 2 & NM_000633 \\
\hline BAX & BCL2-associated X protein & NM_138761 \\
\hline FAS & Fas (TNF receptor superfamily, member 6) & NM_000043 \\
\hline BIRC5 & Baculoviral IAP repeat-containing 5 (survivin) & NM_001168 \\
\hline \multicolumn{3}{|l|}{ Control } \\
\hline АCTB & actin, $B$ & NM_001101 \\
\hline
\end{tabular}

Western blots for SSAT and SMO. The cells were lysed in RIPA buffer and equal amounts of total protein from different cell lines were loaded (for SSAT $80 \mu \mathrm{g}$ and for SMO $60 \mu \mathrm{g}$ ) onto 12 and 10\% SDS-PAGE gels, respectively, followed by transfer to polyvinylindene difluoride membrane and immunoblotted with specific antibodies. SSAT was detected 
Table II. Comparison of changes in gene expression (increase or decrease relative to untreated control) in A2780 cells following treatment with Pt (II) spermine, Pd (II) spermine and Cispt, DENSPM or Cispt/DENSPM under the same treatment conditions.

\begin{tabular}{lccccc}
\hline Gene & CisPt & DENSPM & CisPt/DEN & Pt (II)-spermine & Pd (II)-spermine \\
\hline SSAT & 33 & 3 & 49 & $\mathrm{NC}$ & $\mathrm{NC}$ \\
SMO & 6 & 3 & 5.9 & 0.18 & 0.13 \\
SAMDC & 0.6 & $\mathrm{NC}$ & 0.5 & $\mathrm{NC}$ & $\mathrm{NC}$ \\
ARG2 & 2.3 & $\mathrm{NC}$ & 2.4 & 0.33 & 0.38 \\
NRF2 & 1.75 & $\mathrm{NC}$ & 2.1 & 0.42 & 0.46 \\
FAS & 16 & $\mathrm{NC}$ & 17 & 1.7 & $\mathrm{NC}$ \\
BAX & 4.5 & $\mathrm{NC}$ & 3.5 & 1.7 & 1.5 \\
BCL2 & 0.43 & $\mathrm{NC}$ & 0.37 & 0.5 & 0.5 \\
BIRC5 (Survivin) & 0.3 & $\mathrm{NC}$ & 0.4 & $\mathrm{NC}$ & $\mathrm{NC}$ \\
P21 & 93 & $\mathrm{NC}$ & 51 & 5 & 2.7 \\
MDM2 & 26 & $\mathrm{NC}$ & 29.7 & $\mathrm{NC}$ & $\mathrm{NC}$ \\
PCNA & 3.3 & $\mathrm{NC}$ & 2.8 & 1.5 & 1.6 \\
ERCC1 & 4 & $\mathrm{NC}$ & 2.6 & 0.6 & 0.6 \\
GGT1 & $\mathrm{NC}$ & $\mathrm{NC}$ & $\mathrm{NC}$ & 0.23 & 0.25 \\
OCT,1 & 3 & $\mathrm{NC}$ & 2.3 & $\mathrm{NC}$ & $\mathrm{NC}$ \\
OGG1 & $\mathrm{NC}$ & $\mathrm{NC}$ & 0.6 & 0.65 & 0.62 \\
PPARG & $\mathrm{NC}$ & $\mathrm{NC}$ & 0.5 & 0.6 & NC \\
PTGS2 (Cox2) & 1.8 & 0.7 & $\mathrm{NC}$ & 0.45 & 0.4 \\
\hline
\end{tabular}

${ }^{a}$ Values are RQ (relative expression, treated/control); rounded off. NC, no change. RQ value $>1$ denotes up-regulation and the value itself describes the fold increase in expression; RQ value $<1$ denotes down-regulation and the value itself is expression as a fraction of control.

as described previously $(29,30)$ and SMO protein was detected using a SMO-specific antibody developed by our laboratories (Vujcic et al, unpublished). Untreated cells were used as a control. NIH3T3 cells treated with DENSPM and A2780 treated with oxaliplatin and DENSPM were used as positive control for SSAT. HCT-116 cells treated with DENSPM, and A2780 treated with oxaliplatin and DENSPM were used as positive controls for SMO.

SSAT activity. SSAT activity assay was performed as described previously (31). In brief, the reaction mixture contained $\left[{ }^{14} \mathrm{C}\right]$ acetylCoA $(60 \mathrm{mCi} / \mathrm{mmol}$, NEN Radiochemicals, Waltham, MA) spermidine and cell extract in Tris-HCl buffer, $\mathrm{pH}$ 7.5. The $\left[{ }^{14} \mathrm{C}\right]$ acetylated spermidine product generated by the enzyme reaction is captured on discs followed by counting of radioactivity. Protein in the cell lysate was determined by the Bradford assay (32). The activity reported is $\mathrm{pmol} / \mathrm{min} / \mathrm{mg}$ protein.

Polyamine pools. Intracellular polyamine pools and acetylated polyamine pools were extracted with $0.6 \mathrm{~N}$ perchloric acid, dansylated and analyzed using reverse phase HPLC with fluorescence detection as previously described (33). Protein was determined by Bradford assay (32). Polyamine pools were expressed as $\mathrm{pmol} / \mathrm{mg}$ protein.

Cytotoxicity assays. Cells were plated in a 96-well plate ( $1 \times 10^{3}$ cells/well) on day 0 followed by exposure to cisplatin,
A.<smiles>NP(N)(Cl)(Cl)Cl</smiles>

B.

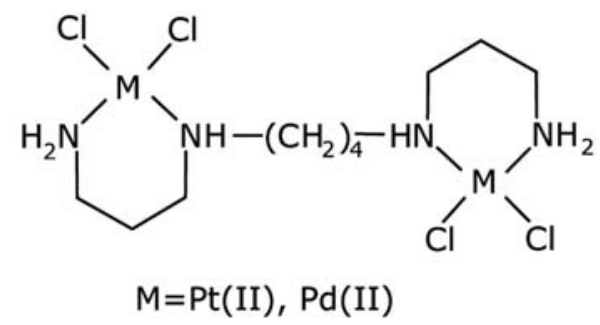

$$
\text { C. } \mathrm{H}_{2} \mathrm{~N}-\left(\mathrm{CH}_{2}\right)_{3}-\mathrm{NH}-\left(\mathrm{CH}_{2}\right)_{4}-\mathrm{NH}-\left(\mathrm{CH}_{2}\right)_{3}-\mathrm{NH}_{2}
$$

Figure 1. Structures of cisplatin (A), Pt, Pd-spermine complexes (B) and spermine (C).

Pt-spermine or Pd-spermine on day 1. Cells were exposed to drug concentrations ranging from 0.1 to $100 \mu \mathrm{M}$ for $72 \mathrm{~h}$, at which point cells were fixed and subjected to the sulforhodamine-B micro-culture colorimetric assay (SRB) (34). Percent survival were determined as [OD570 (treated cells)/ OD570 (untreated cells)]*100. 


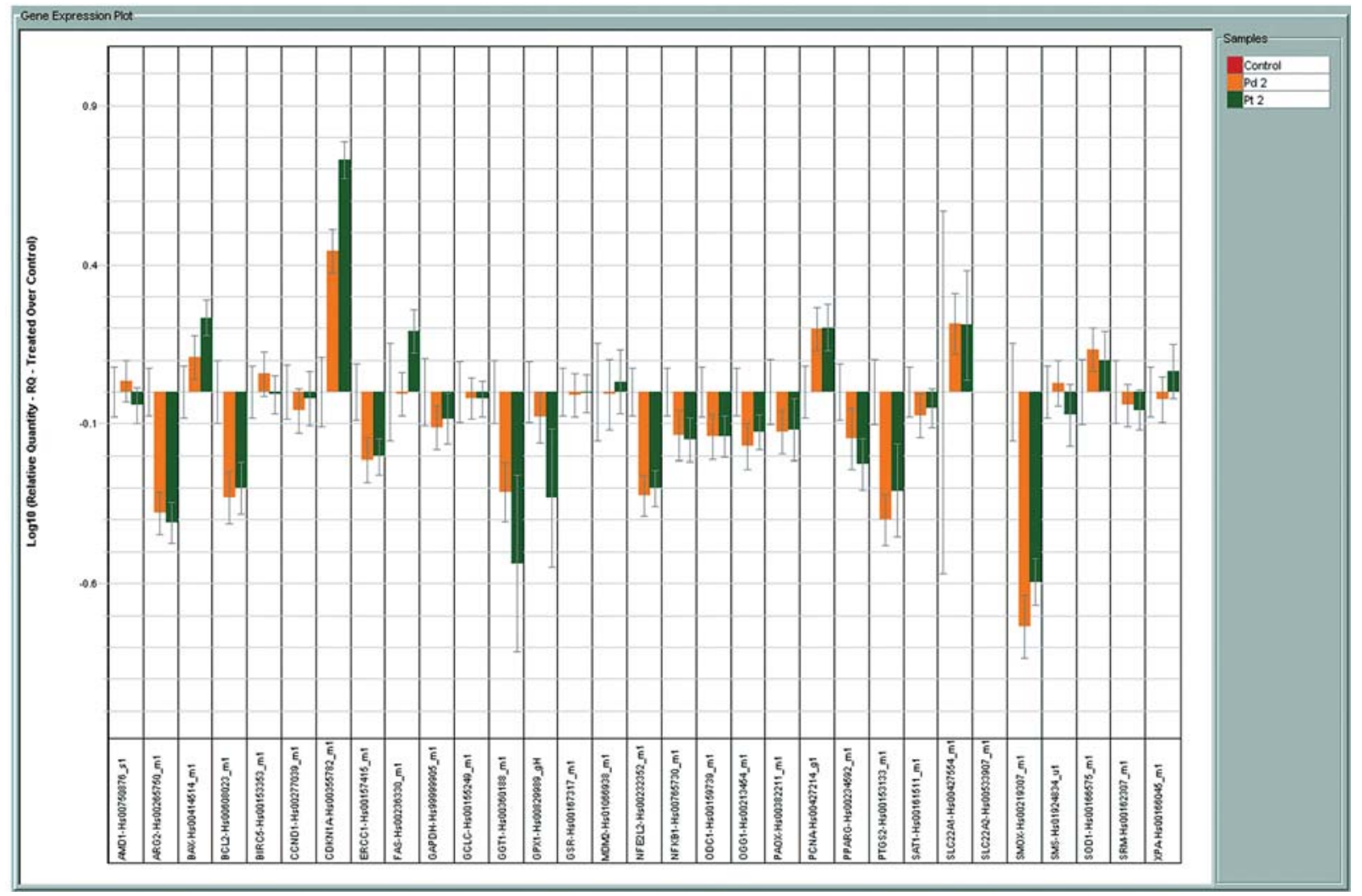

Figure 2. Expression of genes represented on TLDA in A2780 human ovarian carcinoma cells treated with Pt-spermine and Pd-spermine complexes. Bars are $\log _{10}$ RQ. RQ is the quantity of expression of a given gene relative to the drug untreated control. Bars going upward represent up-regulation and those going downwards down-regulation. Error bars are the confidence intervals compared to the no-drug controls in the first position of each cluster.

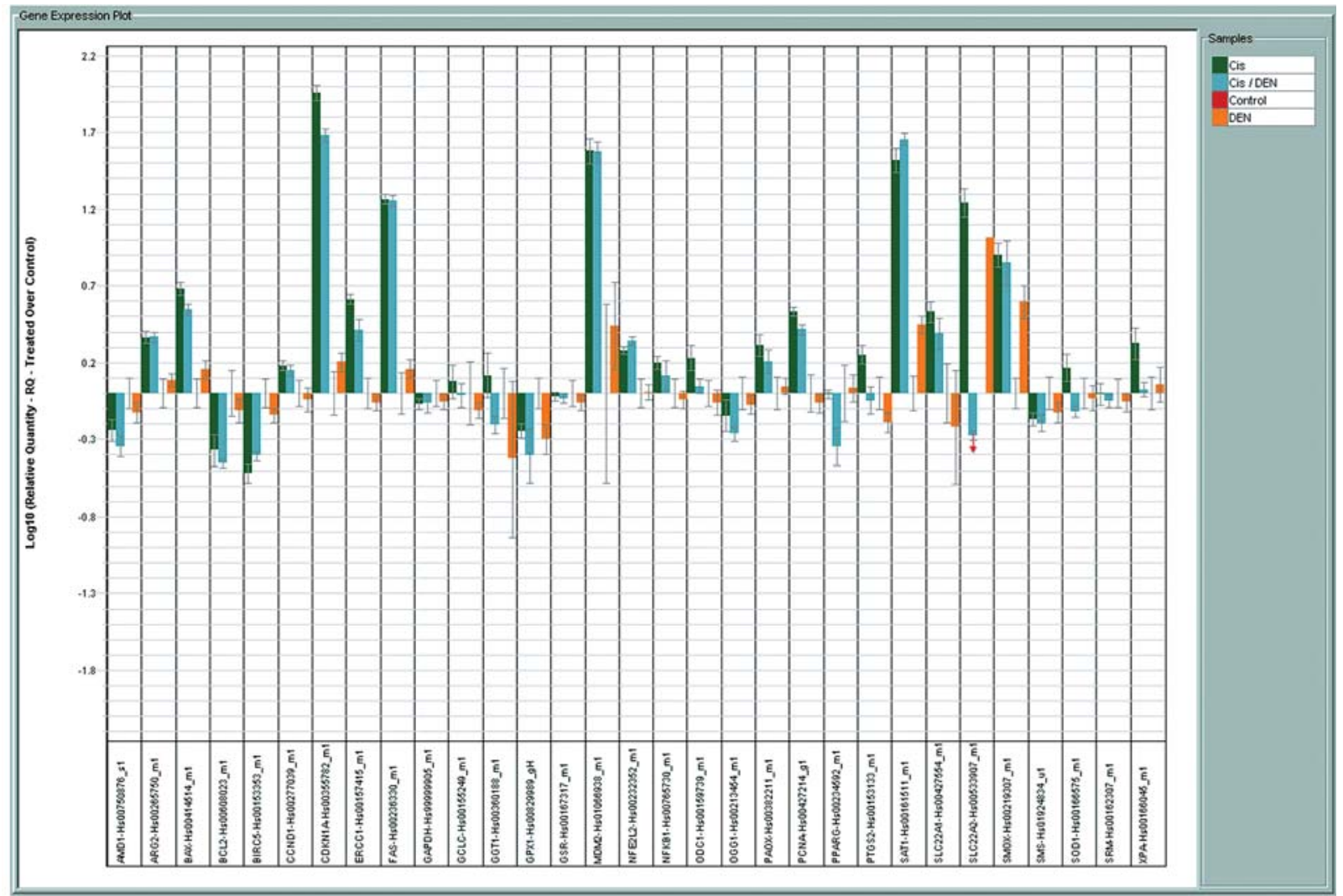

Figure 3. Expression of genes represented on TLDA in A2780 ovarian carcinoma cells treated with cisplatin, DENSPM or cisplatin/DENSPM. Bars are log 10 RQ. RQ is the quantity of expression of a given gene relative to the drug untreated control. Bars going upward represent up-regulation and those going downwards down-regulation. Error bars are the confidence intervals compared to the no-drug controls in the third position of each cluster. 
A

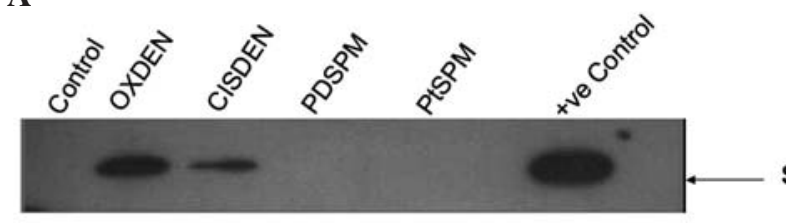

B

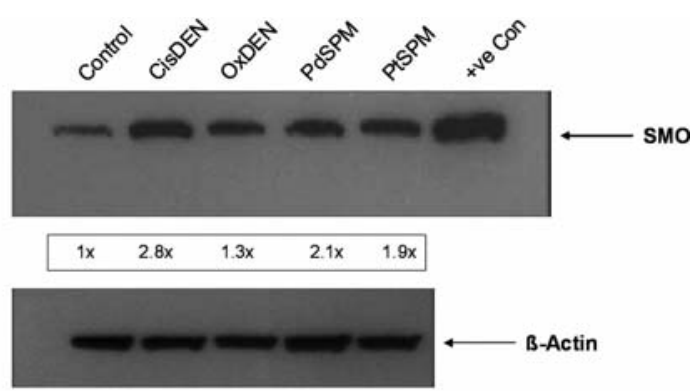

Figure 4. Western blot analysis of SSAT (A) and SMO (B). A2780 cells were treated with Pd-spermine, Pt-spermine or cisplatin/DENSPM, all at $10 \mu$ M concentration each for $20 \mathrm{~h}$ followed by $24 \mathrm{~h}$ incubation in drug free medium. The cells were harvested thereafter and $60-80 \mu \mathrm{g}$ of whole cell extracts were used for Western blot and probed with human SSAT antibody (A) or SMO antibody (B). Untreated cells were used as control for both. NIH3T3 cells treated with DENSPM were used as a positive control for SSAT (A) and HCT-116 cells treated with oxaliplatin/DENSPM were used as a positive control for SMO (B). A2780 cells treated with oxaliplain/DENSPM were also used as a positive control for SSAT and SMO. Note that fold changes could not be presented in 4A, as controls had no measurable SSAT protein.

\section{Results}

Effect of Pt-spermine and Pd-spermine on gene expression. The effect of the Pt- and Pd (II) spermine agents on our custom panel of 30 genes relevant to platinum and polyamine drug action (TLDA) in comparison to cisplatin/DENSPM was studied in A2780 ovarian carcinoma cells. A representative experiment for the gene expression data obtained from the $\mathrm{Pt}$ (II) spermine and Pd (II) spermine complexes is shown in Fig. 2. Data from cisplatin, DENSPM or cisplatin/DENSPM treatment of A2780 cells is shown in Fig. 3. Key for the genes on the TLDA card is included in Table I. The gene expression plots in Figs. 1 and 2 show the log RQ for each of the genes. RQ is the gene expression normalized to $\beta$-actin for each of the genes in each sample and presented relative to the no-drug control. The log plots of RQ show the down-regulation of genes much better than the linear plots and present a balanced view of the up or down-regulated genes which makes it easier to compare the gene expression differences between treatments. The gene expression plots show the data in alphabetical order (as dictated by the software) and not as genes in select groups shown in Table I. Note that the order of plots for each gene and for each of the treatments in Figs. 2 and 3 are also in alphabetical order; thus, no-drug controls are shown in the 3rd position in Fig. 3. The error bars here represent the confidence interval (CI) based on a t-test and not standard deviations. The CI for each of the genes in no-drug controls represents the variability of control replicates for those specific genes and makes it easier to select the CI non-overlapping genes between drug treated and controls as the significantly up- or down-regulated genes after the drug treatments. Of those genes that showed significant changes, the extent of up- or down-regulation (RQ values) after each of the drug treatments relative to the no-drug controls is summarized in Table II.

As seen from log RQ plots (Fig. 2) the Pt and Pd complexes have a very similar profile of up- or down-regulation of the genes represented on this card, suggesting that it may be the polyamine portion of the molecule conferring the changes in gene expression rather than the metal. The Pt-spermine and $\mathrm{Pd}$-spermine complexes induced more down-regulation of genes than up-regulation (Fig. 2), as opposed to cisplatin and
Table III. Spermidine/Spermine $\mathrm{N}^{1}$ acetyltransferase (SSAT) ${ }^{\mathrm{a}}$ activity after treatment with Pt-spermine or Pd-spermine.

\begin{tabular}{lc}
\hline Treatment & $\begin{array}{c}\text { SSAT activity } \\
\text { (pmols/min/mg) }\end{array}$ \\
\hline Control & $15.5 \pm 3.3$ \\
Pd-Spm & $11.5 \pm 4.6$ \\
Pt-Spm & $12.1 \pm 0.8$ \\
\hline
\end{tabular}

${ }^{\mathrm{a} A 2780}$ cells were treated with Pd-spermine or Pt-Spermine $(10 \mu \mathrm{M})$ for $20 \mathrm{~h}$ followed by $24 \mathrm{~h}$ in drug free medium. The cells were harvested thereafter and assayed for SSAT. Untreated cells were used as controls. Data are an average of 3 measurements.

cisplatin/DENSPM combinations that induced more upregulation of genes (Fig. 3). From the plots and the data summarized in Table II, it can be seen that the most significant differences (directional differences in expression) are in genes related to the polyamine pathway. Pt-, Pd-spermine complexes induced significant down-regulation of SMO, arginase 2 and NRF-2, while no significant change was noted for SSAT. Under the same treatment conditions, cisplatin as single agent or in combination with DENSPM induced significant upregulation of both SSAT and SMO and down-regulated SAMDC. For the most part, Pt- and Pd-spermine complexes showed similar effects on apoptosis and cell cycle genes as cisplatin and cisplatin/DENSPM ( $\uparrow$ FAS, $\uparrow$ BAX, $\downarrow$ BCL-2, $\uparrow \mathrm{p} 21, \uparrow \mathrm{PCNA})$, but to a significantly lower degree. While cisplatin or cisplatin/DENSPM up-regulated ERCC1, the Pt-, Pd-spermine complexes down-regulated the expression of this gene. BIRC5 (survivin) was down-regulated by cisplatin and cisplatin/DENSPM combination while the Pt- and Pd-spermine complexes did not have an effect on this gene. Pt-, Pd-spermine complexes down-regulated the PTGS2 (Cox-2) gene.

SSAT and SMO protein or activity. Consistent with the gene expression data, the SSAT protein (Fig. 4A) or activity (Table III) was not induced by either Pt- or Pd-spermine in A2780 cells. Induction of SSAT protein is evident under the 
Table IV. Polyamine pools after treatment with Pt-spermine or Pd-spermine.

\begin{tabular}{lccr}
\hline Treatment & $\begin{array}{c}\text { Putrescine } \\
(\text { pmols/mg protein) }\end{array}$ & $\begin{array}{c}\text { Spermidine } \\
\text { (pmols/mg protein) }\end{array}$ & $\begin{array}{c}\text { Spermine } \\
(\text { pmols/mg protein) }\end{array}$ \\
\hline Control & $2,151 \pm 537$ & $28,269 \pm 1,187$ & $20,347 \pm 703$ \\
Pd-spermine & $714 \pm 401$ & $17,606 \pm 1,359$ & $14,673 \pm 1,344$ \\
Pt-spermine & $2,479 \pm 627$ & $33,379 \pm 6,142$ & $25,838 \pm 4,948$ \\
\hline
\end{tabular}

A2780 cells were treated with Pd-spermine or Pt-Spermine $(10 \mu \mathrm{M})$ for $20 \mathrm{~h}$ followed by $24 \mathrm{~h}$ in drug free medium. The cells were harvested thereafter and assayed for polyamine pools. Untreated cells were used as controls. Data are an average of 3 measurements.

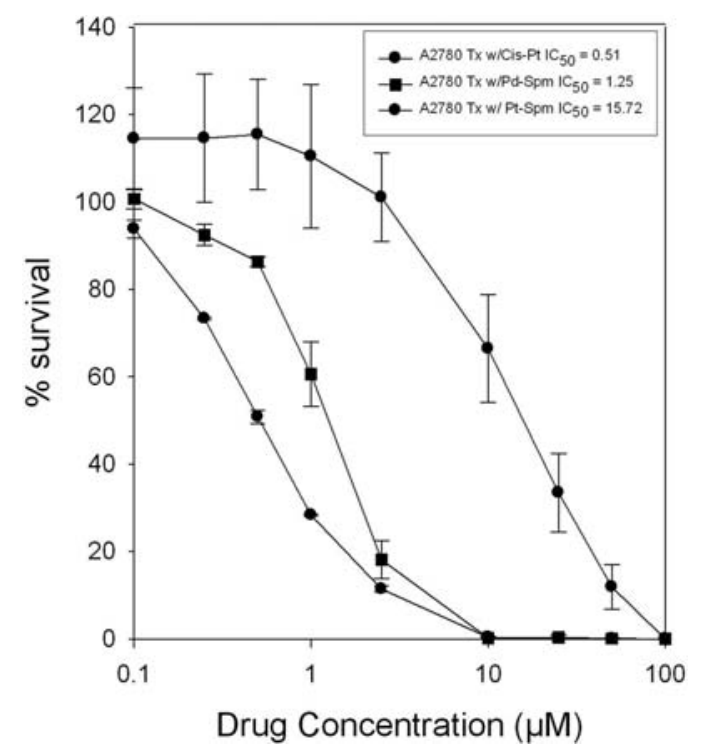

Figure 5. Relative cytotoxic potency of cisplatin, Pt-spermine and Pd-spermine in A2780 cells. Cells were plated in a 96 well plate $\left(1 \times 10^{3}\right.$ cells/well) on day ' 0 ', followed by treatment with cisplatin or Pd-Spermine or Pt-spermine on day 1 at concentrations ranging from 0.1 to $100 \mu \mathrm{M}$ for $72 \mathrm{~h}$. Cells were then fixed and subjected to sulforhodamine-B-microculture colorimetric assay (SRB). Percent survival was determined as $\left(\mathrm{OD}_{570}\right.$ treated cells $/ \mathrm{OD}_{570}$ untreated cells) x100. Data presented are an average of 2 separate experiments, each experiment consisting of 5 replicates of each agent tested.

same conditions for cisplatin/DENSPM combination (Fig. 4A). Although SMO gene expression showed a significant downregulation after both $\mathrm{Pt}$ - and $\mathrm{Pd}$-spermine, interestingly SMO protein levels were significantly elevated compared to the nodrug control and to a similar extent as the cisplatin/DENSPM treated cells (Fig. 4B).

Polyamine pools. Changes in polyamine pools in A2780 cells after Pt-spermine or Pd-spermine are shown in Table IV. The Pd-spm treatment decreased putrescine levels to $33 \%$, spermidine to $62 \%$ and spermine to $72 \%$ relative to the no-drug controls, while Pt-spm did not induce such a decline.

Cytotoxicity profiles of the Pt- and Pd-spermine complexes in relation to cisplain in $A 2780$ cells. Comparative cytotoxicity profiles of cisplatin, Pt-Spm and Pd-Spm in A2780 cells shown in Fig. 5 indicate the potency to be cisplatin $>\mathrm{Pd}-$ Spm $>$ Pt-Spm with $\mathrm{IC}_{50}$ values of $0.51,1.25$ and $15.72 \mu \mathrm{M}$, respectively.
Cross-resistance patterns of the complexes with cisplatin in a cisplatin resistant ovarian carcinoma cell line A2780/CP. The A2780/CP cell line is $\sim 12$-fold resistant to cisplatin (Fig. 6). A comparison of the Pt-spermine and Pd-spermine cytotoxicity in A2780/CP cells and parental A2780 cells indicate that their potency is lower than cisplatin, however, the Pt-spermine exhibits only a 2.5 -fold cross resistance and the $\mathrm{Pd}$-spermine exhibiting $\sim 7.5$-fold cross resistance. Thus, cisplatin resistant cells appear to be sensitive to Ptspermine.

\section{Discussion}

A significant body of studies accumulated in the last several years indicate that platinum drugs have an effect on the polyamine pathway $(6,7,17,18,35,36)$. Our own Affymetrix experiments with oxaliplatin and cisplatin indicate that both of these drugs up-regulated the polyamine catabolic pathway enzymes SSAT and SMO and down-regulated the biosynthetic pathway enzymes SAMDC and ODC (6). A study from our laboratory and others have shown that while platinum drugs are potent inducers of SSAT gene expression, the gene expression does not translate into activity $(7,17,18)$. However, when oxaliplatin is combined with a polyamine analog such as DENSPM a synergistic increase in SSAT activity occurs $(7,17,18)$ with concurrent polyamine pool depletion $(7,17)$. We hypothesized that Pt-, Pd-spermine complexes may possibly have an impact on polyamine pathway and polyamine pools since they represent a composite of two cisplatin molecules (or Pd-diammine dichloride molecules) that are linked to a spermine in the center.

Using TLDA we were able to compare the effect of these complexes with that of cisplatin and cisplatin/DENSPM combination on the expression of genes not only in the polyamine pathway, but also those in other pathways relevant to platinum drug action. As indicated from the data presented, cisplatin up-regulated the expression of FAS, BAX, P21, MDM-2 and PCNA and down-regulated the expression of the anti-apoptotic gene BCL-2 as known from its mode of action (5). Combining DENSPM with cisplatin, did not alter cisplatin effects on these genes. The Pt- and Pd-spermine complexes showed qualitatively similar changes as cisplatin (or cisplatin/ DENSPM) in the expression of the above mentioned cell cycle and apoptosis genes although with a much lower magnitude, indicating that these complexes may kill the cells with similar mechanisms as cisplatin. 
A

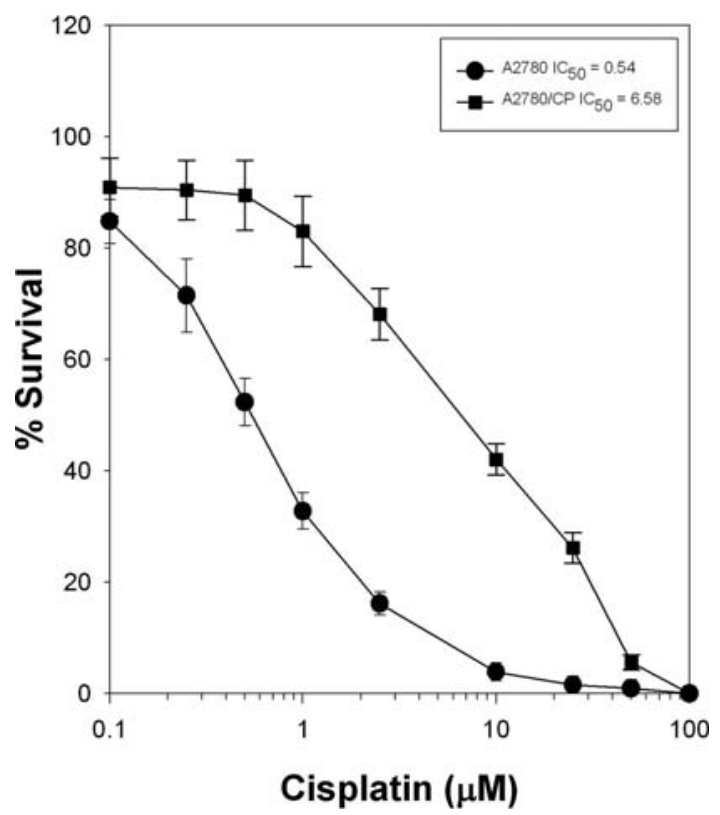

C

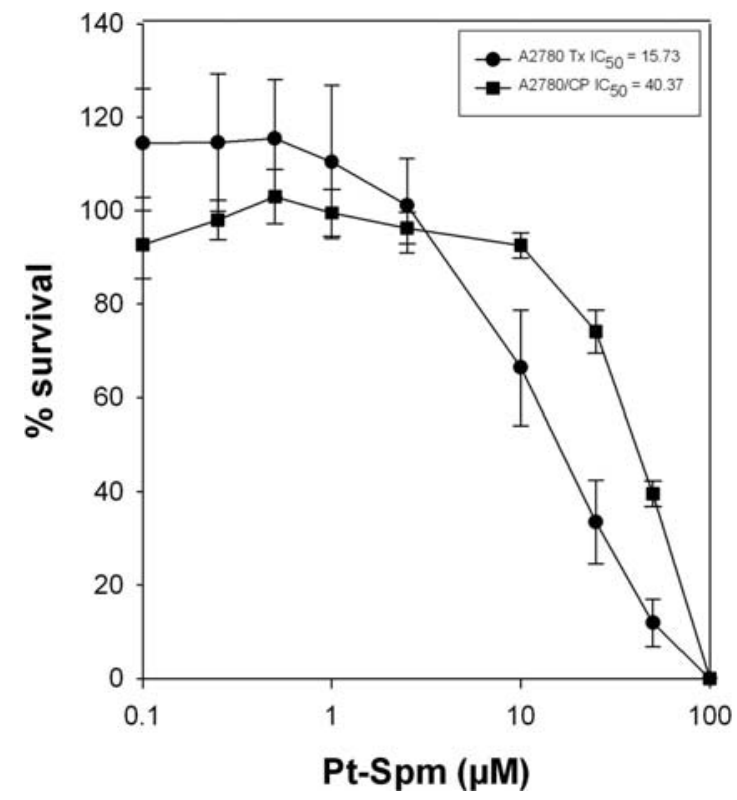

The most significant difference between cisplatin (or cisplatin/DENSPM) and the Pt-, Pd-spermines were found in their potential to affect on the polyamine pathway. When cisplatin up-regulated the expression of SSAT and SMO genes, the Pt- or Pd-spermine treated A2780 cells exhibited down-regulation of SMO and no-change in the expression of SSAT compared to the no-drug controls. Unlike cisplatin, the Pt-, Pd-spermine complexes down-regulated the expression of ARG2 and NRF2. Although SMO gene expression is downregulated, it is intriguing that SMO protein levels are comparatively elevated by Pt-, Pd-spermine complexes similar to cisplatin/DENSPM or oxaliplatin/DENSPM treated cells. It may possibly be that these complexes stimulate translation, and stabilize the SMO protein similar to that known for polyamine interactions with SSAT (37). However, this remains to be determined.

It is quite interesting that while both complexes induced an increase in SMO protein and had no effect on SSAT
B

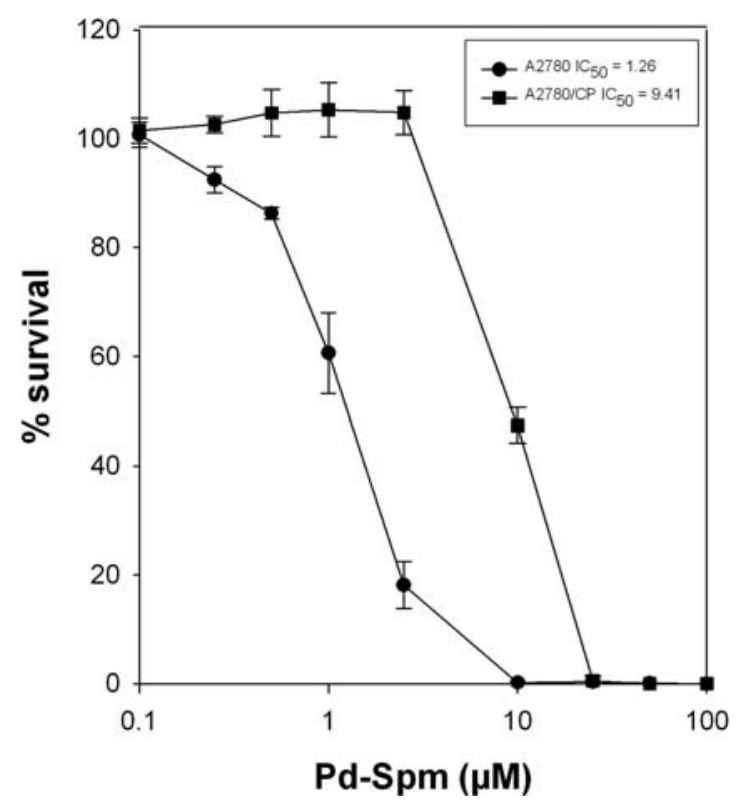

Figure 6. Cross resistance patterns for Pt (II) spermine and Pd (II) spermine in A2780/CP cisplatin resistant cells. Comparison of cytotoxicity in A2780 vs. A2780/CP cells for (A) cisplatin, (B) Pd-spermine and (C) Pt-spermine complexes. Data presented are an average of 2-3 separate experiments, each experiment consisting of 5 replicates of each agent tested.

protein or activity, only the Pd-spm treatment induced a fall in putrescine levels to $33 \%$, spermidine to $62 \%$ and spermine to $72 \%$ relative to the no-drug controls. It is unclear exactly what these changes are due to, since at the gene expression level neither of these compounds had an effect on the biosynthetic pathway genes ODC and SAMDC. It may also be related to intracellular concentration and/or metabolism attained for these complexes and further studies are necessary to unravel some of these differences.

We also tested the cytotoxicity profiles of these compounds in comparison to cisplatin in the A2780 ovarian carcinoma cells, the cells used for the gene expression and polyamine pathway alterations discussed above. These studies indicated the potency for these 3 agents to be cisplatin $>$ Pd-Spm $>$ PtSpm with $\mathrm{IC}_{50}$ values of $0.52,1.32$ and $12.7 \mu \mathrm{M}$, respectively. Thus some of the differences seen between Pt-spermine and Pd-spermine may be related to the potency of these compounds, related to differences in uptake, further metabolism, or effective concentrations for reaching the target. We also tested the two drugs for their cytotoxicity in a cisplatin resistant cell line (A2780/CP) relative to the parental cell line, to understand their cross resistance patterns to cisplatin. As evident from the data, although both drugs exhibit a lower potency relative to cisplatin, the degree of resistance itself is much lower for Pt-spermine and Pd-spermine in that order (2.5 and 7.5, respectively) compared to cisplatin $(\sim 12)$. While Pt-spermine may be more effective in cisplatin resistant cells in vitro, because of the very low potency, the concentrations required to kill the cells may not be achievable in an in vivo setting. However, the overall data with respect to polyamine pool depletion as well as the potency and cross-resistance patterns suggest that the Pd-spermine complex may prove to be a useful agent for further investigations in vitro and in vivo. 
Our previously obtained results point to a different mechanism of action of Pd-spermine as compared to cDDP, leading to a synergetic interaction when these two agents are co-administered. It was also verified that Pd-spermine is responsible for a damaging interaction with DNA, although the exact nature of this interplay remains to be understood (experiments performed by the authors to check for interstrand crosslinks with DNA were not conclusive, Fiuza et al, unpublished data). In light of these results, Pd (II)polyamine complexes constitute a promising group of inorganic compounds for the development of novel chemotherapy/adjuvant chemotherapy strategies.

\section{Acknowledgements}

This study was supported by RO1CA109619 from the National Cancer Institute. The content is solely the responsibility of the authors and does not necessarily represent the official views of the National Cancer Institute and the National Institutes of Health. We acknowledge the support of NCI Comprehensive Cancer Center grant CA10656 for the PK/PD Core Facility usage.

\section{References}

1. Wang D and Lippard SJ: Cellular processing of platinum anticancer drugs. Nat Rev Drug Discov 4: 307-320, 2005.

2. Andrews PA: Mechanisms of acquired resistance to cisplatin. Cancer Treat Res 73: 217-248, 1994.

3. Rabik CA and Dolan ME: Molecular mechanisms of resistance and toxicity associated with platinating agents. Cancer Treat Rev 33: 9-23, 2007.

4. Gosland M, Lum B, Schimmelpfennig J, Baker J and Doukas M: Insights into mechanisms of cisplatin resistance and potential for its clinical reversal. Pharmacotherapy 16: 16-39, 1996.

5. Siddik ZH: Cisplatin: mode of cytotoxic action and molecular basis of resistance. Oncogene 22: 7265-7279, 2003.

6. Varma R, Hector S, Greco WR, Clark K, Hawthorn L, Porter C and Pendyala L: Platinum drug effects on the expression of genes in the polyamine pathway: time-course and concentrationeffect analysis based on Affymetrix gene expression profiling of A2780 ovarian carcinoma cells. Cancer Chemother Pharmacol 59: 711-723, 2007.

7. Hector S, Porter CW, Kramer DL, Clark K, Prey J, Kisiel N, Diegelman P, Chen Y and Pendyala L: Polyamine catabolism in platinum drug action: Interactions between oxaliplatin and the polyamine analogue $N^{l} N^{11}$-diethylnorspermine at the level of spermidine/spermine $N^{l}$-acetyltransferase. Mol Cancer Ther 3: 813-822, 2004

8. Tummala R, Porter CW, Diegelman P, Vujcic S, Clark K, Prey J, Kisiel N, Kramer D and Pendyala L: Platinum drug effects on polyamine enzymes in A2780 human ovarian carcinoma cells. Proc Am Assoc Cancer Res 48: Abs 365, 2007.

9. Thomas T and Thomas TJ: Polyamines in cell growth and cell death: molecular mechanisms and therapeutic applications. Cell Mol Life Sci 58: 244-258, 2001.

10. Porter C, Herrera-Omelas L, Pera P, Petrelli NF and Mittleman A: Polyamine biosynthetic activity in normal and neoplastic human colorectal tissues. Cancer 60: 1275-1281, 1987.

11. Leveque J, Foucher F, Bansard JY, Havouis R, Grall JY and Moulinoux JP: Polyamine profiles in tumor, normal tissue of the homologous breast, blood, and urine of breast cancer sufferers. Breast Cancer Res Treat 60: 99-105, 2000.

12. Thomas T, Balabhadrapathruni S, Gallo MA and Thomas TJ: Development of polyamine analogs as cancer therapeutic agents. Oncol Res 13: 123-135, 2002.

13. Creaven PJ, Perez R, Pendyala L, Meropol NJ, Loewen G, Levine E, Berghorn E and Raghavan D: Unusual central nervous system toxicity in a Phase I study of N1N11 diethylnorspermine in patients with advanced malignancy. Invest New Drugs 15: 227-234, 1997.
14. Streiff RR and Bender JF: Phase 1 study of $N^{l} N^{11}$-diethylnorspermine (DENSPM) administered TID for 6 days in patients with advanced malignancies. Invest New Drugs 19: 29-39, 2001.

15. Hahm HA, Ettinger DS, Bowling K, Hoker B, Chen TL, Zabelina Y and Casero RAJ: Phase I study of $N^{I} N^{11}$-diethylnorspermine in patients with non-small cell lung cancer. Clin Cancer Res 8: 684-690, 2002.

16. Wolff AC, Armstrong DK, Fetting JH, Carducci MK, Riley CD, Bender JF, Casero RAJ and Davidson NE: A Phase II study of the polyamine analog $N^{l} N^{11}$-diethylnorspermine (DENSpm) daily for five days every 21 days in patients with previously treated metastatic breast cancer. Clin Cancer Res 9: 5922-5928, 2001.

17. Hector S, Tummala R, Kisiel ND, Diegelman P, Vujcic S, Clark K, Fakih M, Kramer DL, Porter CW and Pendyala L: Polyamine catabolism in colorectal cancer cells following treatment with oxaliplatin, 5-fluorouracil and $N^{I} N^{11}$-diethylnorspermine. Cancer Chemother Pharmacol 62: 517-527, 2008.

18. Allen WL, McLean EG, Boyer J, McCulla A, Wilson PM, Coyle V, Longley DB, Casero RA Jr and Johnston PG: The role of spermidine/spermine $N^{I}$-acetyltransferase in determining response to chemotherapeutic agents in colorectal cancer cells. Mol Cancer Ther 6: 128-137, 2007.

19. Ray S, Mohan R, Singh JK, Samantaray MK, Shaikh MM, Panda D and Ghosh P: Anticancer and antimicrobial metallopharmaceutical agents based on palladium, gold, and silver N-heterocyclic carbene complexes. J Am Chem Soc 129: 15042-15053, 2007.

20. Kuduk-Jaworska J, Puszko A, Kubiak M and Pelczynska M: Synthesis, structural, physico-chemical and biological properties of new palladium (II) complexes with 2,6-dimethyl-4-nitropyridine. J Inorg Biochem 98: 1447-1456, 2004.

21. Mansuri-Torshizi H, Ghadimy S and Akbarzadeh N: Synthesis, characterization, DNA binding and cytotoxic studies of platinum (II) and palladium (II) complexes of the 2,2'-bipyridine and an anion of 1,1-cyclobutanedicarboxylic acid. Chem Pharm Bull 49: $1517-1520,2001$.

22. Fiuza SM, Amado PJ, Oliveira VA, Sardao VA, Batista de Carvalho LAE and Marques MPM: Pt (II) vs Pd (II) polyamine complexes as new anticancer drugs: a structure-activity study. Lett Drug Des Discov 3:149-151, 2006.

23. Teixeira LJ, Seabra M, Reis E, da Cruz MT, de Lima MC, Pereira E, Miranda MA and Marques MP: Cytotoxic activity of metal complexes of biogenic polyamines: polynuclear platinum (II) chelates. J Med Chem 47: 2917-2925, 2004.

24. Butour JL, Wimmer S, Wimmer F and Castan P: Palladium(II) compounds with potential antitumour properties and their platinum analogues: a comparative study of the reaction of some orotic acid derivatives with DNA in vitro. Chem Biol Interact 104: 165-178, 1997.

25. Jodrell DI, Evans TR, Steward W, Cameron D, Prendiville J, Aschele C, Noberasco C, Lind M, Carmichael J, Dobbs N, Camboni G, Gatti B and De BF: Phase II studies of BBR3464, a novel tri-nuclear platinum complex, in patients with gastric or gastro-oesophageal adenocarcinoma. Eur J Cancer 40: 1872-1877, 2004.

26. Soares AS, Fiuza SM, Concalves MJ, de Caravalho LAEB, Marques MPM and Urbano AM: Effect of metal center ib tge antitumor activity of the analogous dinuclear spermine chelates (PdCl2)2(spermine) and (PtCl2)2(spermine). Lett Drug Des Discov 4: 460-463, 2007.

27. Varma R, Hector S, Greco WR, Clark K, Hawthorn L, Porter C and Pendyala L: Platinum drug effects on the expression of genes in the polyamine pathway: time-course and concentrationeffect analysis based on Affymetrix gene expression profiling of A2780 ovarian carcinoma cells. Cancer Chemother Pharmacol 59: 711-723, 2007.

28. Brun YF, Varma R, Hector SM, Pendyala L, Tummala R and Greco WR: Simultaneous modeling of concentration-effect and time-course patterns in gene expression data from microarrays. Cancer Genomics Proteomics 5: 43-53, 2008.

29. Fogel-Petrovic M, Vujcic S, Brown PJ, Haddox MK and Porter CW: Effects of polyamines, polyamine analogs, and inhibitors of protein synthesis on spermidine-spermine $N^{I}$-acetyltransferase gene expression. Biochemistry 35: 14436-14444, 1996.

30. Chen Y, Kramer DL, Jell J, Vujcic S and Porter CW: Small interfering RNA suppression of polyamine analog-induced spermidine/spermine $N^{l}$-acetyltransferase. Mol Pharmacol 64: 1153-1159, 2003 
31. Porter CW, Ganis B, Libby PR and Bergeron RJ: Correlations between polyamine analogue-induced increases in spermidine/ spermine $N^{I}$-acetyltransferase activity, polyamine pool depletion, and growth inhibition in human melanoma cell lines. Cancer Res 51: 3715-3720, 1991.

32. Bradford MM: A rapid and sensitive method for the quantitation of microgram quantities of protein utilizing the principle of protein-dye binding. Anal Biochem 52: 5115-5118, 1976.

33. Vujcic S, Halmekyto M, Diegelman P, Gan G, Kramer DL, Janne J and Porter CW: Effects of conditional overexpression of spermidine/spermine N1-acetyltransferase on polyamine pool dynamics, cell growth, and sensitivity to polyamine analogs. J Biol Chem 275: 38319-38328, 2000.

34. Rubinstein LV, Shoemaker RH, Paull KD, et al: Comparison of in vitro anticancer drug screening data generated with a tetrazolium assay versus a protein assay against a diverse panel of human tumor cell lines. J Natl Cancer Inst 82: 1113-1118, 1990 .
35. Maxwell P, Longley DB, Latif T, Boyer J, Allen W, Lynch M, McDermott U, Harkin D, Allegra CJ and Johnston PG: Identification of 5-fluorouracil-inducible target genes using cDNA microarray profiling. Cancer Res 63: 4602-4606, 2003.

36. Boyer J, Allen WL, McLean EG, Wilson PM, McCulla A, Moore S, Longley DB, Caldas C and Johnston PG: Pharmacogenomic identification of novel determinants of response to chemotherapy in colon cancer. Cancer Res 66: 2765-2777, 2006.

37. Casero RAJ and Pegg AE: Spermidine/spermine $N^{l}$-acetyltransferase-the turning point in polyamine metabolism. FASEB J 7: 653-661, 1993 . 